\title{
POLA PERGESERAN NILAI KEARIFAN LOKAL SISTEM LADANG BERPINDAH PADA MASYARAKAT ARFAK
}

\section{CHANGE OF PATTERNS LOCAL VALUE OF SHIFTING CULTIVATION IN ARFAK COMMUNITIES}

\author{
Yuliana Ataribaba ${ }^{1}$, Iwan Setiawan ${ }^{2}$, Trisna Insan Noor ${ }^{2}$ \\ ${ }^{1}$ Politeknik Pembangunan Pertanian (Polbangtan) Manokwari Papua Barat \\ ${ }^{2}$ Departemen Sosial Ekonomi Pertanian dan Sekolah Pascasarna Unpad \\ *Email: ataribabaeunike@gmail.com
}

(Diterima 21-06-2020; Diterima 22-07-2020)

\begin{abstract}
ABSTRAK
Perladangan berpindah merupakan bentuk sistem pertanian tradisional yang sudah melembaga dan membudaya pada Suku Arfak. Sebagai sebuah kearifan lokal, sistem perladangan berpindah penting untuk dipertahankan guna menjaga ketahanan pangan lokal. Tujuan penelitian ini untuk mendeskripsikan pola perladangan berpindah, mengidentifikasi nilai-nilai kearifan lokal (Igya Ser Hanjob); dan menganalisis faktor-faktor yang mempergaruhi pergeseran nilai-nilai kearifan lokal. Untuk itu digunakan desain penelitian kuantitatif dengan teknik survey. Data primer yang terkumpul dari hasil wawancara terstruktur dengan 78 responden dengan menggunakan alat bantu kuesioner, dianalisis dengan menggunakan statistik deskriptif. Hasil penelitian mengungkap bahwa pola perladangan berpindah telah mengalami pergeseran. Pergeseran terjadi pada waktu tanam dan rentang (luasan) berladang. Terkait dengan ladang berpindah, suku Arfak memiliki nilai kearifan lokal turun-temurun yang disebut Igya Ser Hanjob (terutama sayang pada lahan adat dan menjaga hutan). Pergeseran itu dipengaruhi oleh tekanan penduduk, perkebunan sawit, kebun keluarga, kebun marga lain, transmigran dan perluasan infrastruktur. Rekomendasinya, diperlukan perlindungan lahan masyarakat dan kearifan lokal secara bersama, melalui integrasi peraturan formal dengan kesepakatan lokal (adat).
\end{abstract}

Kata kunci: pola pergeseran, nilai-nilai lokal, sistem ladang berpindah

\begin{abstract}
Shifting cultivation is a form of traditional agricultural system that has been institutionalized and entrenched in the Arfak tribe. As a local wisdom, a shifting cultivation system is important to maintain in order to protec of local food security. The purpose of this study is to describe shifting cultivation patterns, identify local wisdom values (Igya Ser Hanjob); and analyze the factors that influence the shift of local wisdom values. For this reason, using a quantitative design and survey method. Primary data collected from interviews with 78 respondence using questionnaires instument, were analyzed using descriptive statistics. The results of the study revealed that shifting cultivation patterns had undergone a shift. Shifts occur at the time of planting and the range (area) of farming. Regarding shifting fields, the Arfak tribe has a value of hereditary local wisdom called Igya Ser Hanjob (especially dear to customary land and protecting forests). The shift was influenced by population pressure, oil palm plantations, family gardens, other clan estates, transmigrants and expansion of infrastructure. The recommendation is to protect community land and local wisdom together, through the integration of formal regulations with local (custom) agreements.
\end{abstract}

Keywords: shift patterns, local values, shifting cultivation systems 
POLA PERGESERAN NILAI KEARIFAN LOKAL

SISTEM LADANG BERPINDAH PADA MASYARAKAT ARFAK

Yuliana Ataribaba, Iwan Setiawan, Trisna Insan Noor

\section{PENDAHULUAN}

Pendekatan kedaulatan pangan sebagai salah satu varian dari konsep ketahanan pangan pertama kali dicetuskan tahun 1996 oleh organisasi buruh tani dan petani dunia yang bernama La Via Campesina. Pada hakekatnya, kedaulatan pangan merupakan hak rakyat, komunitas dan negara untuk menentukan kebijakan dan strategi mereka sendiri atas produksi, distribusi dan konsumsi pangan yang berkelanjutan. Harapannya, akan terjamin hak atas pangan bagi seluruh penduduk bumi berdasarkan produksi yang beragam, berskala kecil dan menengah. Menghargai kebudayaan sendiri, keberagaman kaum tani-nelayan dan teknologi produksi pertanian lokal. Selain itu, juga menghargai peran perempuan dalam pengelolaan input, produksi, hasil dan pemasaran di pedesaan (Fakih, 2001).

Pada prinsipnya, kedaulatan pangan meliputi (Hines, 2000; IFPRI, 2001; Raj Patel, 2009; Salma Loudiyi, 2009; Suryana, 2007; Wittman, 2010; Marc Edelman et al, 2014): a) akses pangan; b) reformasi agraria; (c) penggunaan sumber daya alam secara berkelanjutan; (d) pangan tidak sekadar komoditas yang diperdagangkan; (e) pembatasan penguasaan pangan oleh korporasi; (f) melarang penggunaan pangan sebagai senjata; (g) pemberian akses ke petani kecil untuk perumusan kebijakan pertanian; (h) prasyarat keberlanjutan pangan; (i) produksi pangan lokal; dan (j) perdagangan yang adil. Secara prinsip ketahanan pangan berbeda dengan kedaulatan pangan. Ketahanan pangan bergerak pada kebutuhan dasar dengan target populasi kurang pangan, berintegrasi pada sistem yang existing, dan peran negara pasif (no obligation, charity).

Sebaliknya, kedaulatan pangan bergerak melampaui (beyond) kebutuhan dasar (termasuk hak sosial, ekonomi dan budaya: hak berproduksi), dengan target petani kecil, menuntut kebijakan alternatif dan menghendaki peran aktif pemerintah sebagai pelindung utama petani. Hak menentukan kebijakan pangan sendiri menegaskan bahwasanya para buruh tani dan petani yang menentukan pilihan cara produksi, teknologi, relasi produksi, distribusi hingga keamanan pangan. Melalui kedaulatan pangan, semua aktivitas produksi pangan dikerjakan para petani sendiri, sehingga kedaulatan pangan dimiliki petani, bukan korporasi. Perspektif alternatif dari Seunghyun Yoo 
et al (2004), René Rohrbeck et al (2013) dan Oades et al (2017) menawarkan pendekatan partisipatif, berbagi dan berkolaborasi dalam melindungi kelompok rentan, termasuk petani kecil.

Hines (2000), Raj Patel (2009) dan Salma Loudiyi (2009) mendefinisikan kedaulatan pangan (food sovereignty) sebagai hak dan kemampuan suatu rumah tangga, suatu masyarakat (community) dan suatu negara untuk menentukan dan mengendalikan sistem (produksi, distribusi, konsumsi, pengelolaan, pengolahan, pemasaran dan pemanfaatan) pangannya sendiri secara berkelanjutan. Termaktub dalam konsep kedaulatan pangan adalah keberagaman, kemandirian dan keamanan pangan. Kedaulatan pangan adalah keberdayaan dan kemandirian suatu bangsa untuk menghasilkan, menyediakan, memenuhi dan mengelola pangannya secara berkelanjutan. Menurut Setiawan et al (2017), untuk mewujudkannya membutuhkan pemihakan dari pemerintah dan pengurangan tingkat konsumsi pangan pokok dari konsumen.

Ladang berpindah merupakan pola pertanian tradisional yang diterapkan secara evolutif oleh masyarakat lokal dalam mewujudkan ketahanan pangan. Meskipun eksistensinya semakin tersisih oleh pertanian modern, namun faktanya masih ada di Indonesia, salah satunya di masyarakat Arfak Papua. Sebuah komunitas lokal yang menempati Pegunungan Arfak di wilayah kepala burung Papua. Entitasnya disebut juga suku besar Arfak, karena terdiri atas beberapa sub suku (Hatam, Moile, Sough dan Meyakh). Wilayah Arfak sebelumnya merupakan bagian dari Kabupaten Manokwari, namun pada tahun 2012 ditetapkan sebagai kabupaten pemekaran baru berdasarkan UU No. 24 tahun 2012.

Masyarakat Arfak,sub Suku Meyakh merupakan masyarakat agraris, yakni masyarakat yang hidupnya sangat bergantung pada pertanian di daratan. Masyarakat Arfak, sub suku Meyakh biasanya menyebut kegiatan bertani yang mereka lakukan dengan istilah berkebun (berladang). Hal ini menegaskan bahwa aktifitas bertani dilakukan di lahan kering (kebun). Berkebun dilakukan semusim sekali (terutama musim hujan) dengan pola ladang berpindah. Pola ini telah melembaga, sehingga menjadi bagian dari budaya lokal. Berkebun tidak hanya dilakukan untuk memenuhi kebutuhan pokok (pangan), tetapi juga menjadi bagian dari sumber penyedia kebutuhan berbagai prosesi adat dan transaksi (alat bayar/denda) adat. 
Ladang berpindah (shifting cultivation) merupakan suatu bentuk sistem pertanian tradisional yang telah lama dipraktekkan di beberapa daerah. Penelitian sebelumnya mengungkap bahwa perladangan berpindah di Papua Barat terdapat di pegunungan Arfak. Hujairin et al (2012) menegaskan bahwa perladangan berpindah bagi masyarakat pedalaman suku Arfak merupakan sistem bertani yang sudah dilakukan secara turun-temurun. Salah satu sub-suku Arfak yang lekat dengan perladangan berpindah adalah Meyakh di Kampung Waseki Pop. Hujairin menegaskan bahwa sub-suku Meyakh memiliki ladang berpindah yang mampu dirotasikan 1-3 kali.

Pola perladangan berpindah sangat lekat dengan nilai-nilai kearifan lokal yang berlaku khusus dalam masyarakat adat suku besar Arfak. Nilai kearifan yang dimaksud adalah budaya Igya Ser Hanjob (berdiri menjaga batas), termasuk menjaga ladang. Secara filosofis, nilai ini mengandung makna bahwa segala yang ada di alam ini (termasuk manusia) memiliki batas. Apabila batas yang ditetapkan dan disepakati dilanggar, maka diyakini akan berbuah bencana. Menurut kosmologi Arfak, segala sesuatu (yang berada di alam semesta) pada hakekatnya bukanlah hal yang tak terbatas (ad infinitum). Segala sesuatu pasti ada batasnya, termasuk batas wilayah adat.

Sejatinya, kearifan lokal tersebut sangat sejalan dengan kebijakan pemerintah yang berkaitan dengan sustainable development goals (SDGs) dan kebijakan ramah lingkungan (green constitution) yang mengedepankan pelestarian sumber daya alam dan lingkungan tanpa harus mengurangi hakhak masyarakat setempat dan generasinya (Rogers et al, 2007; Asshiddiqie, 2009). Salah satunya dalam bentuk pengelolaan dan memanfaatkan hutan secara partisipatif untuk menopang gerak kehidupan masyarakat lokal secara berkelanjutan. Terpeliharanya lingkungan hidup di kawasan pegunungan Arfak jelas akan berdampak positif dan antisipatif terhadap ancaman bencana alam, baik banjir, longsor, kekeringan maupun kelaparan.

Ketaatan masyarakat akan nilainilai igya ser hanjob dalam menjalankan kegiatan berkebun semestinya dapat terus terpelihara, dijaga dan dipatuhi. Namun, eksistensi sumberdaya, nilai-nilai kearifan dan kelembagaan lokal tersebut semakin terancam oleh adanya pengembangan perkebunan dan wilayah perkotaan. Terutama dengan 
meningkatnya permintaan atas lahan untuk perkebunan, infrastuktur, pemukiman transmigran dan pencetakan sawah baru. Sebagai catatan, pada tahun 2017 saja pengembangan perkebunan mencapai 53.806 ha, pertambangan seluas 89.256 ha dan pencetakan sawah baru seluas 1.055 ha (Dinas Pertanian Papua Barat, 2017). Modernisasi dan industrialisasi pertanian dipastikan akan mereduksi ladang-ladang berpindah dan nilai-nilai yang melingkupinya.

Secara statistik, kebutuhan lahan untuk infrastruktur, pertambangan, perkebunan dan pencetakan sawah baru yang cukup besar, diduga telah berdampak negatif terhadap keberlanjutan dan pola perladangan berpindah masyarakat lokal. Jika dibiarkan tidak terkendali, maka dapat mengancam keberlanjutan budaya tani yang telah dilembagakan dan diwariskan secara turun temurun. Akan mengancam keberlanjutan budaya berkebun (ladang berpindah), terutama dengan adanya program cetak sawah baru, pengembangan pertambangan dan perkebunan sawit. Secara internal, pemerintah daerah dan Kepala Suku Besar Arfak pun turut mendukung program tersebut, bahkan mengajak pemilik hak ulayat.
Tulisan ini bertujuan untuk: (1) mendeskripsikan eksistensi dan pergeseran nilai-nilai lokal masyarakat Arfak, khususnya yang berkaitan dengan praktik dan pola perladangan berpindah (igya ser hanjob); (2) mendeskripsikan tingkat kepatuhan masyarakat Arfak terhadap nilai-nilai kearifan lokal, khususnya terkait dengan aktivitas perladangan berpindah (igya ser hanjob) yang telah lama melembaga dan membudaya; dan (3) menganalisis faktorfaktor dominan yang mempengaruhi pergeseran nilai kearifan lokal pada pola perladangan berpindah masyarakat Suku Arfak, sub Suku Meyakh di Kampung Waseki Pop, Distrik Prafi.

\section{METODE PENELITIAN}

Subyek dalam penelitian ini adalah masyarakat Arfak di Papua Barat, sedangkan obyek penelitiannya adalah pergeseran nilai-nilai kearifan lokal sistem perladangan berpindah (igya ser hanjob). Penelitian berparadigma positivistik ini didesain secara kuantitatif dengan menggunakan metode survey deskriptif. Penelitian dilakukan mulai bulan April 2017 sampai Mei 2018 di Desa (Kampung) Waseki Pop, Kecamatan (Distrik) Prafi Kabupaten Manokwari, Provinsi Papua Barat. 
Pemilihan lokasi tersebut didasarkan beberapa pertimbangan sebagai berikut: (1) daerah transisi; (2) eskalasi pengembangan pemukiman (termasuk transmigrasi) sangat cepat; pembangunan infrastrukturnya sangat intensif dan signifikan; (4) wilayah pengembangan perkebunan sawit; (5) menjadi zona eksploitasi pertambangan; dan (6) menjadi salah satu wilayah penyebaran suku Arfak yang menjadi masyarakat asli Manokwari.

Data sekunder dikumpulkan melalui studi literatur (desk study) dari kantor kampung dan dinas teknis terkait, sedangkan data primer dikumpulkan langsung dari 78 responden melalui teknik wawancara terstruktur dengan menggunakan kuesioner yang telah diuji validitas dan reliabilitasnya. Responden yang jumlahnya ditetapkan dengan menggunakan rumus Slovin tersebut diambil secara acak dengan menghindari bias lokasi, gender, komoditas dan elit. Pengumpulan data primer juga dilakukan melalui pengamatan langsung (observasi) dan dokumentasi proses. Data primer yang berhasil dikumpulkan, kemudian ditabulasi dan dianalisis dengan dua pendekatan, yakni statistik deskritif dan statistik inferensi. Statistik deskripsi digunakan untuk mendeskripsikan semua variabel, sedangkan analisis statistik inferensi digunakan untuk mengetahui faktor-faktor dominan yang mempengaruhi pergeseran nilai-nilai pola perladangan berpindah (igya ser hanjob). Alat analisis statistik inferensi yang digunakan adalah analisis jalur (path analysis).

\section{HASIL DAN PEMBAHASAN}

Secara geografis, dari luas keseluruhan Kampung Waseki Pop yang mencapai $2.500,25$ ha, sekitar 2.218 ha $(88,80 \%)$ merupakan kawasan hutan. Sedangkan sisanya digunakan untuk perkebunan (9,20\%), pekarangan, fasilitasi umum dan tegalan. Bagi masyarakat Arfak di Kampung Waseki Pop, hutan, ladang dan pekarangan merupakan ruang produksi dan sumber pangan. Ada enam jenis pangan pokok yang dikembangkan masyarakat Arfak, yakni padi, jagung, kacang tanah, ubi kayu, keladi dan ubi jalar. Secara historis, padi tergolong belum lama diadopsi oleh masyarakat Arfak. Komoditas ini pertama kali diperkenalkan oleh pemerintah lewat penyuluh pertanian lapangan (PPL) dan dikembangkan secara intensif oleh transmigran asal Jawa, Bali, Madura, Sulawesi dan Nusa Tenggara. 
Selain untuk memenuhi kebutuhan hidup sehari-hari, hasil produksi keenam pangan tersebut pun dijual sebagai sumber pendapatan keluarga. Atinya, paradigma ketahanan pangan masyarakat Arfak sudah mengalami evolusi dari subsistensi ke semi komersial, dari barter ke transaksi monetisasi. Menurut McCaston dan Suryana (Wahyu dan Setiawan, 2017) kondisi pangan masyarakat Arfak sudah terdiversifikasi dan swasembada. Bahkan, keragamannya menegaskan sudah berdaulat dan berkelanjutan. Persoalannya, pendekatannya belum diarahkan pada keamanan pangan yang menekankan pentingnya aspek gizi pangan di tingkat individu. Hortikultura dikembangkan, namun belum intensif. Beberapa jenis buah-buahan (pisang, mangga dan durian) sudah umum, sedangkan sayuran masih terbatas.

Perkebunan kelapa, kakao dan sawit dikembangkan secara besar-besar di kampung Waseki Pop. Sawit dikembangkan di lahan petani melalui pola kemitraan dengan perusahaan, terutama di Distrik Prafi. Beberapa ternak yang dikembangkan masyarakat Arfak, seperti sapi, babi dan ayam. Meskipun dikembangkan oleh 37,10 persen penduduk, sapi belum dikandangkan (diikat di pekarangan). Babi merupakan ternak yang sudah lama didomestikasi masyarakat Arfak, namun karena tidak dikandangkan secara permanen (bahkan dilepas), maka oleh perusahaan dan petani sawit dikategorikan sebagai pengganggu utama (hama) tanaman sawit.

\section{Pergeseran Pola Perladangan Berpindah}

Masyarakat Arfak, yang sehari-hari dijuluki "orang arfak", pada umumnya hidup menyebar di bagian timur wilayah Kepala Burung, terutama di kawasan pedalaman Pegunungan Arfak, Kabupaten Manokwari. Secara geografis, wilayahnya didominasi pegunungan. Topografinya berbukit dan bergelombang, dangan puncak tertinggi 2.900 mdpl. Pegunungan Arfak disebut pedalaman (indon) dan masyarakat yang mendiaminya disebut masyarakat "indon". Namun, sejak kedatangan suku pesisir, transmigran dan lainnya, masyarakat Arfak disebut "masyarakat pegunungan".

Suku Besar Arfak terdiri atas empat (4) sub Suku, yaitu : Hatam, Meyakh, Moile dan Sougb. Keempatnya memiliki kesamaan budaya, namun berbeda bahasa. Suku Arfak tersebar di Manokwari, Bintuni, Teluk Wondama, 
Manokwari Selatan, Pegunungan Arfak, Tambrauw dan Maybrat. Sub Suku Hatam menghuni pegunungan Arfak bagian utara (distrik Oransbari dan Ransiki), sub Suku Meyakh menghuni bagian barat (Diatrik Prafi), sub Suku Sougb mendiami bagian selatan (Distrik Anggi) dansub suku Moile menghuni wilayah bagian timur (ditrik Minyambouw).

Sub Suku Meyakh merupakan penduduk asli pedalaman Kabupaten Manokwari yang menghuni Kampung Waseki Pop, Distrik Prafi. Kehidupannya sangat tergantung pada ladang dan hutan. Bagi mereka, hutan memiliki banyak fungsi, baik sebagai sumber makanan, air, energi (kayu bakar), perlindungan (konservasi) dan sebagainya. Pembangunan telah memicu pergeseran pada berbagai aspek kehidupan subsuku Meyakh, bahkan melahirkan masyarakat transisi. Masyarakat yang tinggal di antara masyarakat tradisional dan masyarakat modern (perkotaan) yang identitas budayanya ganda. Tenaga kerja muda mulai beralihke sektor industri yang berkembang di perkotaan dan pinggiran kota.

Menurut Wanki Moon (2012), Wanki Moon et al (2016) dan Wanki Moon et al (2017), masyarakat lokal identik dengan sistem pertanian terpadu, multi fungsi dan berkelanjutan. Secara ekonomi, diversifikasi berfungsi mengantisipasi ragam kebutuhan (berdasarkan jangka waktu), ragam kemungkinan kegagalan dan mengantisipasi (mitigasi) dampak perubahan musim. Secara ekologis, keragaman juga ditujukan untuk pelestarian keragaman hayati, perlindungan sumber air, penyediaan pakan ternak, konservasi dan sebagainya. Sedangkan secara sosiologis, diversifikasi ditujukan untuk literasi (pembelajaran) kepada generasi, menjaga keberlanjutan sosial budaya, perlindungan sosial, adaptasi dan sebagainya.

Pada kenyataannya, perembesan budaya dari masyarakat pendatang dan rekayasa sosial oleh pemerintah melalui program pembangunan telah mengakibatkan terjadinya pergeseran alokasi sumberdaya alam yang pada akhirnya diikuti dengan pergeseran nilainilai kearifan lokal, termasuk pola perladangan berpindah (Gambar 1). Pola pertama masih berjalan normal. Adat istiadat dan nilai-nilai kearifan lokal masih kuat. Masyarakat masih tinggal di pedalaman dengan lahanyang luas, sehingga rotasi perladangan berpindah 
masih panjang ( \pm 7 tahun). Pada pola kedua mulai terjadi pergeseran, ditandai denganadanya pemendekan rotasi lahan (kurang lebih 3 tahun), pemendekan jarak antar kebun dan penyempitan luas zona ladang berpindah. Pada pola ketiga, ladang berpindah semakinsempit, sehingga rotasi lahan menjadi semakin singkat (kurang lebih 5 bulan) dan jarak antara kebun lama dan kebun baru hanya sekitar 30 meter.

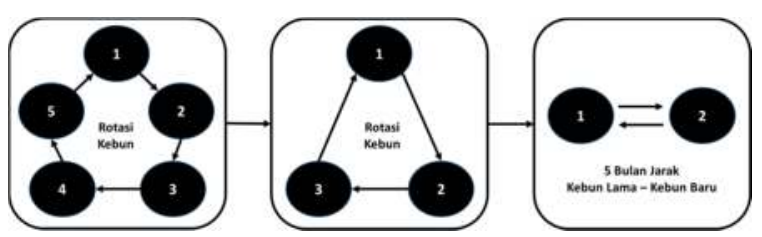

Gambar 1. Pergeseran Pola Perladangan Berpindah Pada Sub Suku Meyakh

Menurut Iskandar (1992), Purwanto (2003) dan Wilson (2007), pergeseran nilai kearifan lokal terjadi karena: (1) tekanan penduduk, (2) berkurangnya tenaga kerja; (3) berkembangnya mekanisme (aturan perladangan), dan (4) adanya gangguan dari daur unsur hara di dalam alam, seperti akibat hutan yang rusak atau adanya erosi tanah dan lainlain. Pergeseran ekstrim (pola perladangan berpindah ke tiga) mulai dirasakan di Kampung Waseki Pop sejak tahun 2008. Hal itu dipicu oleh adanya konversi lahan akibat tekanan penduduk dan masuknya perusahaan kelapa sawit. Namun, konversi lahan yang signifikan terjadi akibat pengembangan perkebunankelapa sawit. Sejatinya, teridentifikasi aspek lain yang menjadi penyebab pergeseran, yakni tidak berjalannya regenerasi pertanian ladang berpindah dan dampak pembangunan (rekayasa sosial) yang menciptakan ketergantungan.

Waseki Pop merupakan salah satu kampung yang didiami transmigran lokal dan menjadi mitra pertama perusahaan sawit. Pada perkembangannya, masyarakat umum Kampung Waseki Pop pun terlibat dalam kemitraan. Menurut Suyanto et al (2017), kemitraan ini lebih mirip rekayasa sosial. Masyarakat melakukan dua aktifitas sekaligus, mengelola sawit miliknya sambil berkebun di lahan kosong sekitar kebun sawit miliknya. Pada umumnya, lahan kosong merupakan kawasan hutan sekunder dan bekas ladang berpindah yang diberakan. Jika meminjam transformasi struktural (Romli et al, 2016), maka industrialisasi pedesaan dan modernisasi pertanian telah berhasil menggeser tenaga kerja dari pertanian tradisional ke pertanian modern (perkebunan sawit), dari sektor pertanian ke non pertanian.

Secara internal, teknologi dan manajemen lahan pun mengalami 
POLA PERGESERAN NILAI KEARIFAN LOKAL

SISTEM LADANG BERPINDAH PADA MASYARAKAT ARFAK

Yuliana Ataribaba, Iwan Setiawan, Trisna Insan Noor

pergeseran dari cara tradisional (menggunakan parang dan tugal) ke penggunaan cangkul dan sekop. Keduanya digunakan untuk membersihkan dan menyiapkan lahan. Penggunaannya telah menggeser babi sebagai sarana menggemburkan tanah. Jika sebelumnya masyarakat melepaskan koloni babi pada lahan yang mau ditanami, sehingga lahan yang diinjak, dikencingi dan dikotori menjadi gembur, sekarang menggunakan teknologi. Pergeseran terkait juga dengan adanya kesepakatan antara masyarakat dengan perusahaan untuk tidak melepas babi, karena mengganggu tanaman sawit. Tampak ada pelemahan institusi lokal, padahal, di Siak Riau, peran institusi lokal tetap dipertahankan (Qomar et al, 2016). Idealnya dapat dibangun model perkebunan yang mengintegrasikan sawit dengan ternak lokal (Subagyono. 2004).

Interaksi masyarakat Arfak dengan transmigran dan industri telah mengubah kebiasaan dalam bertani. Inovasi teknik bercocok tanam di kebun diadopsi dari perkebunan dan demonstrasi plot para penyuluh lapangan. Namun, kebiasaan berkebun dengan pola campuran (tumpang sari multifungsi), dalam satu luasan kebun, tetap dipertahankan. Begi mereka, multiple-cropping sudah menjadi kebiasaan turun temurun. Menurut Akca et al (2005) dan Leakey (2017), pertanian multifungsi merupakan identitas petani lahan kering. Pola ini dipertahankan, karena menjaga keberlanjutan sosial, ekonomi dan ekologi. Selain itu, perubahan perilaku tidak mungkin berjalan secara mendadak (Sumardjo, 1999). Butuh proses belajar dan modal sosial, apalagi masyarakat Arfak yang berpendidikan formal rendah, patuh pada adat dan terikat pola ladang berpindah.

Jika dianalisis dengan teori konstruksi sosial (Ngange, 2011; Setiawan et al, 2016), dapat ditegaskan bahwa proses pelembagaan (globalism) di masyarakat Arfak lebih dominan dibanding proses internalisasi nilai-nilai lokal (glocalism). Ketimpangan ini membuat proses dialektika lokal-global tidak terjadi. Implikasinya, pendekatan lokal termarginalkan dan pendekatan luar mengambang. Sangat wajar apabila masyarakat lokal memandang sinis terhadap setiap program pembangunan. Komoditas yang diusahakan masih didominasi tanaman pangan, disamping ragam tanaman lainnya yang tidak terlalu membutuhkan banyak air (pisang, pepaya dan rambutan). Selain dijadikan konsumsi keluarga, pangan lokal juga digunakan untuk upacara adat. Namun, 
masuknya beras telah menggeser pangan lokal (keladi, ubi jalar, sagu). Akibatnya, orientasi pengembangan pangan lokal bergeser dari subsistensi ke semi komersial. Ironi, pada akhirnya, hasil penjualan pangan lokal digunakan untuk membeli beras.

Tidak terciptanya dialektika lokalglobal telah menggeser nilai dalam berbagai hal, tidak terkecuali nilai-nilai kearifan yang terkait dengan panen dan pascapanen. Sejak beras dikenal sebagai pangan pokok, pola panen tanaman pangan lokal berubah. Jika semula cara panen dilakukan secara bertahap (sesuai kebutuhan) dan dengan upaca adat, maka sekarang dilakukan serentak (massal). Tidak ada upacara, karena hasil panen langsung dijual ke pasar, baik ke pasar Prafi maupun ke Kota Manokwari (pasar Sanggeng dan pasar Wosi). Rasionalitas ekonomi menjadi lebih dominan daripada moralitas ekonomi dan otonomi (Scott, 1993; Pranadji, 1999). Orientasi subsistensi mulai tereduksi relasi ekonomi-pasar yang transaksional. Hal ini menegaskan, meskipun tidak berjalan sekaligus, pergeseran nilai kearifan lokal tidak bersifat bagian per bagian (partial), tetapi menyeluruh (holistik), menyangkut nilai-nilai budaya masyarakaat (Van der Ploeg, 2008; Setiawan et al, 2015).
Secara riil, teknik bertani dan berkebun masyarakat Arfak di Kampung Wasegi Pop belum bergeser. Meskipun waktu dan jaraknya semakin singkat, namun sistem ladang berpindah masih tetap bertahan. Bagi mereka, berkebun secara menetap hanya dilakukan pada komoditas sayuran (terutama kacang kedelai dan kacang tanah) yang diintroduksikan dari luar melalui pemerintah (dinas terkait dan penyuluh lapangan). Mereka menyiapkan lahan khusus yang akan ditanami dan akan menanaminya ketika sudah ada bantuan bibit. Bagi mereka, program ini merupakan milik dinas, bukan kebutuhan mereka, sehingga tidak memelihara atau merawatnya. Fenomena seperti ini umum terjadi dan merupakan bentuk rekayasa sosial yang tidak berkelanjutan di Papua. Idealnya, proses seperti itu dilakukan melalui pemberdayaan yang menumbuhkan partisipasi lokal dari mulai pembenihan, produksi, pemasaran dan pengolahan (Simon, 2001; Supyandi et al, 2016). Menurut Maudia Camalin et al (2017), perubahan sosial tidak cukup dilakukan melalui rekayasa, tetapi harus sesuai nilai dan kebutuhan lokal masyarakat.

Dalam sistem perladangan berpindah tradisional, pengerjaan lahan 
dilakukan secara gotong-royong, mulai dari tahap pembukaan lahan, pembersihan areal kebun, pembuatan pagar sampai panen. Kini gotong-royong sudah tidak tampak lagi, karena ikatan kekeluargaan marga dan warga lokal sudah memudar bersama tereduksinya lahan-lahan perladangan berpindah dan masuknya suku-suku sekitar (Biak, Serui, Sorong, Jawa). Kolektifitas sudah tergeser oleh sistem upahan dan relasi transaksional, kehadiran lapangan kerja baru dan migrasi ke sektor industri. Jika tidak menggunakan tenaga kerja dalam keluarga, maka berkebun harus mengupah tenaga kerja dari luar, terutama suku Jawa dari daerah transmigrasi. Ironi, setiap keluarga telah terkooptasi tanggungjawabnya masingmasing. Namun demikian, sebagai modal sosial, gotong-royong masih dijumpai pada kegiatan selain berkebun. Meminjam istilah Grootaert (1997) dan Cook et al (1997), nilai tukar sosial (berbagi dan berkolaborasi) yang semula melekat kuat dalam masyarakat adat Arfak, kini telah tergeser oleh nilai tukar ekonomi yang didesakan dari luar.

Tingkat Kepatuhan Masyarakat Suku Arfak Terhadap Nilai Kearifan Lokal Igya Ser Hanjob

Terkait dengan tradisi, nilai-nilai lokal dan kontestasinya dengan modernitas, teori strukturasi Anthony Giddens (2003) menyatakan bahwa "kemodernan bukanlah akhir dari sejarah kehidupan, tradisi pasti berubah, tetapi nilai integritas dan keberlanjutannya tidak pernah tereliminasi dari generasi ke generasi, bahkan untuk ekologis dan moralitas, tradisi dan nilai-nilai lokal telah lama mematahkan klaim kemodernan. Secara empiris, tradisi eksis dalam masyarakat adat, masyarakat yang hidup menyatu dengan alam, mengedepankan harmoni dan relasi seimbang, baik dengan Tuhan, sesama manusia maupun dengan alam. Mereka hidup adaptif, antisipatif, bersahaja dan berpandangan ke depan, tetapi kukuh pada kerarifan lokal. Namun demikian, kenyataan menunjukan bahwa masyarakat lokal di Indonesia semakin tersisih oleh entitas luar yang kuat kuasa, baik birokrasi maupun korporasi yang mendesakan modernisasi.

Masyarakat Arfak memiliki nilai dan kearifan budaya lokal yang disebut Igya Ser Hanjob yang artinya berdiri menjaga batas $($ Igya $=$ berdiri, Ser $=$ menjaga, dan hanjob = batas). Secara filosofis, nilai ini bermakna segala sesuatu yang ada di alam ini memiliki batas. Apa yang dibatasi? Kampung, tanah ulayat, hutan, ladang, pekarangan, 
kekuasaan, perilaku dan sebagainya. Jika batas itu dilanggar, maka diyakini akan berbuah bencana. Menurut Mulyadi (2007), Igya Ser Hanjob adalah konsep pembagian batas wilayah konservasi lahan dan cara berkebun secara rotasi untuk menjaga kelestarian hayati. Ini merupakan konsep originalitas, karena dipegang taguh oleh masyarakat Arfak dan diwariskan secara turun temurun. Sebagai sebuah nilai, ia menjadi landasan hidup masyarakat Arfak sehari-hari. Melalui Igya Ser Hanjob dikenal empat batasan kawasan dalam mencari kehidupan sehari-hari, yakni bahamti, nimahanti, susti dan situmti. Seperti halnya pranata mangsa (Adimiharja, 1999), keempat aturan tersebut didasarkan pada tanda-tanda alam dan perubahan lingkungan.

Konsep Igya Ser Hanjob adalah konsep pembagian batas wilayah konservasi lahan dan cara berkebun secara rotasi untuk menjaga kelestarian hayati dan keseimbangan ekosistem. Kapasitas lahan yang mencerminkan kesuburan lahan menjadi dasar rotasi. Sangat rasional, karena produktifitas semakin melandai (stagnant). Batas pengelolaan ditujukan untuk pemulihan kesuburan lahan dengan mengandalkan ragam tanaman yang tumbuh kembang di atasnya. Tujuan utama dari rotasi adalah menjamin produktifitas, produksi yang berkelanjutan dan meminimalkan tindakan ekploitasi lahan yang tidak terkendali. Oleh karena itu, rotasi ada batas waktu, batas lokasi dan ada batas luasan (skala usaha) yang ditetapkan berdasarkan kesepakatan kolektif masyarakat adat. Titik-titik rotasi ladang berpindah sudah terpola dan dilembagakan adat secara turun temurun. Jejak inilah yang kemudian ditetapkan sebagai dasar dalam penetapan suatu kawasan sebagai lahan ulayat atau tanah adat (Thamrongwarangkul, 2001; Mulyo Utami et al, 2004).

Secara kelembagaan, dalam masyarakat yang berpijak pada adat istiadat, Igya Ser Hanjob merupakan budaya asli masyarakat Suku Besar Arfak yang sangat dipatuhi, dipegang teguh dan diwariskan secara turun temurun. Idealitasnya, kepatuhan masyarakat terhadap nilai-nilai Igya ser hanjob tergambar pada pola pengelolaan sumber daya alam, terutama dalam pemanfaatan kawasan ladang berpindah. Menurut Mulyadi (2012), masyarakat Arfak mengenal empat pembagian wilayah tempat mereka mencari kehidupan seharihari. Pertama, kawasan Bahamti, yakni hutan asli (primer) yang dijaga ketat 
masyarakat. Pada zona ini sangat dilarang berkebun, menebang kayu, berburu dan bermukim. Namun, pada batas-batas tertentu, diperbolehkan mengambil kulit kayu, daun untuk atap rumah, tanaman obat dan rotan. Kini Bahamti mulai tereduksi dari sistem sosial, bahkan tidak menjadi acuan bagi para pendatang. Implikasinya, kerusakan hutan terjadi di mana-mana, terutama akibat pembukaan lahan untuk perkebunan (Biswas, 2010; Herman dan Handewi, 2004).

Kedua, kawasan Nimahanti, yakni bekas kebun yang ditinggalkan (masa lahan diistirahatkan atau diberakan) selama 10-20 tahun. Pepohonannya sudah besar, bahkan hampir mirip dengan kawasan Bahamti. Pada kawasan ini diperbolehkan mengambil kulit kayu, rotan, daun, berburu serta boleh membuka ladang (berkebun), namun tidak diperbolehkan membangun rumah (pemukiman). Kini pada sebagian lokasi, daerah ini sudah berganti menjadi areal pertambangan dan perkebunan. Bahkan, sebagian sudah berganti menjadi pemukiman. Ketiga, kawasan Susti, yakni kawasan pengelolaan yang lahannya dapat digarap sebagai ladang atau kebun; dan Keempat, kawasan Situmti, yakni bekas kebun yang lokasinya berdekatan dengan perkampungan atau halaman rumah. Ini merupakan kawasan terbuka yang ditanami umbi-umbian, sayursayuran dan lain-lain. Kebaikan dan kontribusi masyarakat Arfak dalam mendukung pembangunan infrastruktur dalam bentuk pemberian ribuah hektar lahan ulayat, telah mengubur ragam budaya, plasma nutfah dan budidayanya. Sebuah kondisi sosial ekonomi yang dianggap biasa pada masyarakat adat, tetapi berumpan balik negatif terhadap kearifan lokal (Funes-Monzote, 2008).

Secara perlahan, kehadiran perkebunan sawit telah menggeser nilainilai bahamti. Investasi sawit, penerapan PIR dan nilai tukar ekonomi telah melonggarkan norma adat dan nilai kearifan lokal bahamti. Peningkatan jumlah penduduk lokal, hadirnya warga pendatang (transmigran, buruh kebun), dan pengembangan kebun sawit, telah menggeser kawasan Nimahanti. Indikatornya terlihat dari masa istirahat lahan yang bergeser dari 7 tahun menjadi 3 tahun, bahkan tinggal 5 bulan. Pergeseran waktu menegaskan bahwa lahan-lahan yang digunakan untuk ladang berpindah sudah beralih fungsi/guna, bahkan sudah beralih pemilikan (Utomo et al, 1992; Wibowo et al, 1996). Perluasan perkotaan, pembangunan fasilitas publik, pembangunan industri, 
perkebunan dan pemukiman yang pesat juga telah meningkatkan alih fungsi lahan di kawasan Susti. Pergeseran yang signifikan terjadi pasca pengembangan perkebunan dan bertambahnya penduduk.

\section{Faktor-Faktor yang Mempengaruhi Pergeseran Nilai-Nilai Kearifan Lokal Igya Ser Hanjob}

Berhasil atau gagal, diterima atau ditolak dan positif atau negatifnya berbagai dampak pembangunan terhadap nilai-nilai kearifan lokal ditentukan oleh faktor internal dan eksternal. Menurut Gestalt, persepsilah yang menjadi pintu dan penentu bagi terjadinya perubahan. Rakhmat (1999) dan Mulyana (2000) menegaskan bahwa proses persepsi berlangsung secara selektif dan sukarela. Seseorang atau komunitas melihat apa yang ingin dia lihat dan mendengar apa yang ingin didengarnya mengabaikan pesan yang lain. Tindakan merupakan hasil kumulatif seluruh proses interaksi, termasuk persepsi dan pengambilan keputusan. Menurus Gelstat, orang mempersepsi tidak bagian per bagian, tetapi keseluruhan. Menurut Rakhmat (1999), penting juga memperhatikan persepsi, baik objek, situasi, yang mempersepsi (perceiver), persepsi diri, maupun pengamatan terhadap orang lain.
Pada kenyataannya, sejak program pembangunan dan pengembangan perkebunan kelapa sawit dioperasikan di wilayah Prafi tahun 2000-2018, sistem mata pencaharian masyarakat sekitar (terutama masyarakat adat) mengalami pergeseran. Pola PIR yang melibatkan masyarakat sekitar (plasma), telah memicu migrasi petani dari ladang berpindah menjadi pekebun sawit dan mendorong migrasi buruh tani menjadi buruh perkebunan. Signifikannya nilai tukar sosial ekonomi (upah dan pendapatan), teridentifikasi sebagai faktor pendorong utama terjadinya migrasi. Persoalannya, semua itu berdampak negatif terhadap lahan, pelaku dan aktifitas ladang berpindah. Bersamaan dengan itu, tumbuh penilaian rendah dari generasi muda Arfak terhadah tradisi ladang berpindah. Implikasinya, nilai kearifan lokal terdegradasi dari dalam (oleh generasi) dan dari luar (oleh mobilitas demografi, modernisasi pertanian, industrialisasi pedesaan dan perluasan perkotaan).

Semakin terbatasnya kawasan susti telah mengakibatkan masyarakat Arfak yang masih menggantungkan hidupnya pada ladang berpindah, mengolah lahan marginal dan bahamti yang ada di pinggiran kebun sawit. Hal ini 
menegaskan bahwa pola perladangan berpindah yang diterapkan masyarakat sudah bergeser ke sistem perladangan semi menetap dan menetap. Ironinya, bukan perubahan sosial yang memicunya, tetapi perubahan lingkungan akibat terjadinya konversi hutan dan ladang berpindah. Normalnya, sistem ladang berpindah dilakukan dengan rotasi kebun lama ke kebun baru kurang lebih 5 tahun, kini tidak lagi seperti itu. Karena lahan semakin terbatas, maka siklus perpindahan menjadi lebih singkat. Kini ladang berpindah yang tersisa hanya berada di pinggiran perkebunan sawit, sehingga rotasi menjadi singkat, dengan luasan yang hanya sekitar $15 \times 20 \mathrm{~m}^{2}$. Fenomena seperti ini, oleh Eric Wolf (1995) disebut kekalahan kaum tani, sedangkan oleh Fakih (2001) dan Shiva (2002) disebut korban pembangunan, yakni "individu dan komunitas yang terpinggirkan secara paksa dari ekosistem dan sosiosistemnya karena adanya program pembangunan yang dioperasikan pihak yang kuat dan kuasa.

Pasca dibukanya perkebunan sawit, lahan untuk kegiatan usahatani menjadi berkurang dan terbatas. Corak dan orientasi usahatani yang dilakukan pun cenderung bergeser dari subsistensi ke semi komersial. Secara riil, jenis tanaman yang diusahakan relatif tidak mengalami banyak perubahan, baik pangan (keladi, betatas, singkong) maupun hortikultura (sayuran dan buah-buahan). Sejatinya, masyarakat dapat memanfaatkan lahan pekarangan yang relatif luas untuk ditanami berbagai jenis sayuran dan tanaman pangan. Persoalannya, tanaman tidak akan aman dari gangguan babi yang dimiliki oleh sebagian besar masyarakat, tetapi tidak dikandangkan. Bahkan, babi masyarakat menjadi gangguan bagi tanaman perkebunan (terutama sawit) yang dikembangkan perusahaan. Menurut Van der Ploeg (2008), pergeseran dari ladang berpindah ke pola usahatani menetap bersifat cacat (acident), karena tidak didasari perubahan perilaku dan sosial yang normal. Implikasinya, pola dan pendekatan apapun yang dijalin (dimitrakan) dengan masyarakat Arfak tidak akan berjalan.

Hasil analisis jalur dengan menggunakan SPSS diketahui bahwa pergeseran nilai-nilai kearifan lokal Igya Ser Hanjob dipengaruhi secara langsung, signifikan dan positif oleh variabel tingkat kepatuhan masyarakat terhadap kearifan lokal $(66,66 \%)$. Pergeseran nilai kearifan lokal juga dipengaruhi secara tidak langsung, positif dan signifikan oleh karakteristik petani $(23,40 \%)$, aspek 
kelembagaan $(9,70 \%)$ dan motivasinya $(39,08 \%)$. Secara langsung, tingkat kepatuhan masyarakat terhadap nilai kearifan lokal dipengaruhi secara positif dan signifikan oleh karakteristik petani, kelembagaan dan motivasi sebesar $72,20 \%$, sedangkan sisanya dipengaruhi oleh faktor lain (Gambar 2). Fakih (2001) dan Shiva (2002) telah mendeteksi kemungkinan terjadinya peminggiran masyarakat lokal oleh korporasi secara fisik (lahan) dan secara budaya. Dipaksa masuk budaya baru tidak menerima, bertahan dengan budaya lama tidak berdaya. Timbul komunitas yang mengangkang (enclave culture) yang akan terus menutut identitasnya, sebut saja suku Kubu (Jambi), dayak (Kaimantan) dan Talang Mama (Riau).

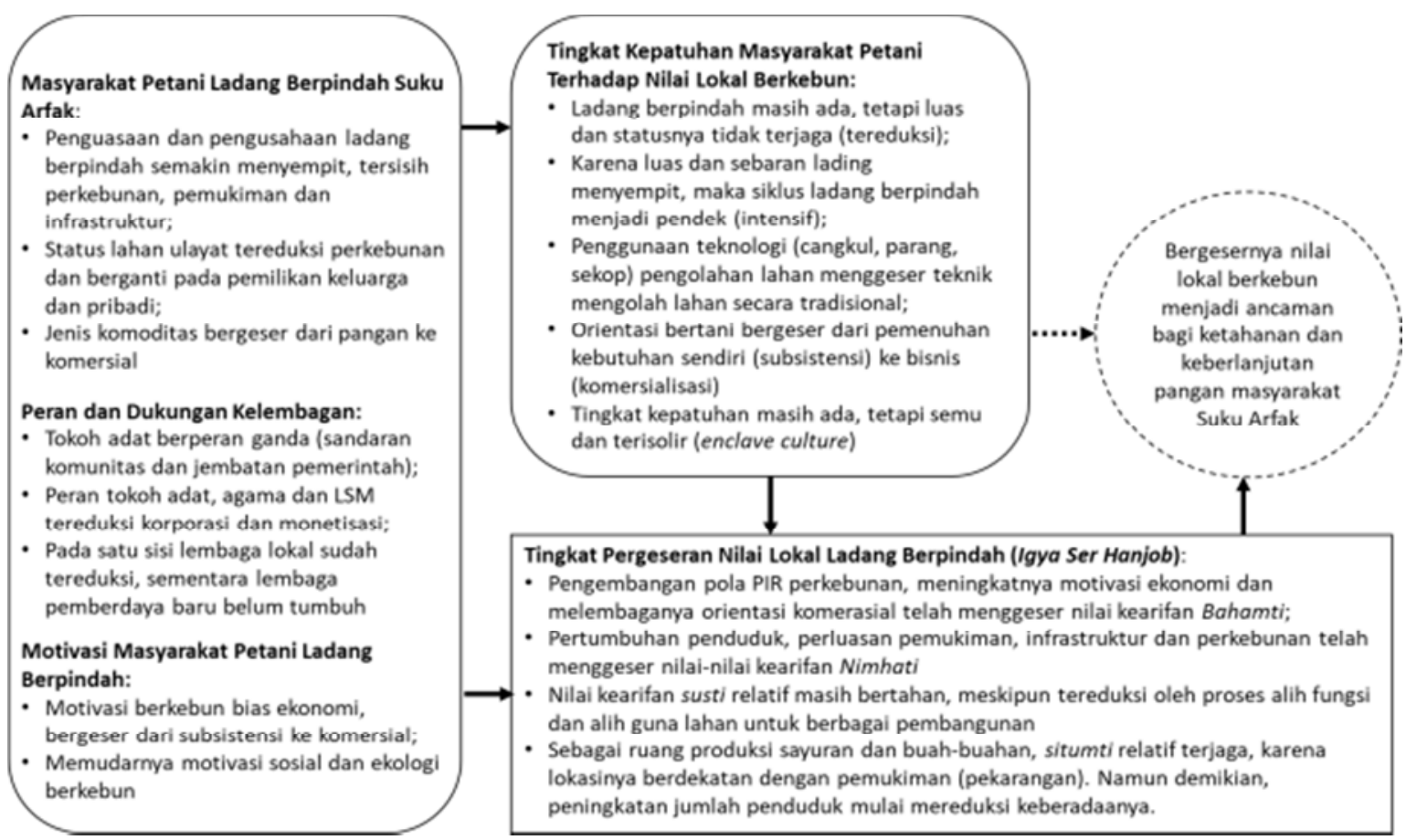

Gambar 2. Faktor Dominan yang Mempengaruhi Pergeseran Nilai Kearifan Lokal Ladang Berpindah (Igya Ser Hanjob) Suku Meyakh

\section{KESIMPULAN}

\section{Kesimpulan}

Berdasarkan masalah yang dirumuskan, dapat disimpulkan: (1) Pola perladangan berpindah masih eksis pada masyarakat suku Arfak, namun waktu rotasi kebun semakin pendek karena jarak perpindahan lahan semakin dekat. Ladang berpindah masih tetap berada dalam kawasan Susti, namun semakin sempit oleh adanya proses alih fungsi yang masif, baik karena pengembangan perkebun, pemukiman pendatang, infrastruktur dan pertambangan. Bagi 
masyarakat Arfak, ladang merupakan pangkal budaya, sehingga ketika ladang terkonversi, maka hampir dipastikan semua nilai lokal yang terkait dengan ladang mengalami pergeseran. Meskipun nilai kearifan lokal Hanjob masih dipertahankan dalam aktivitas ladang berpindah/berkebun, namun sejatinya telah kalah oleh berbagai pendekatan pembangunan yang didesakan dari perkotaan; (2) Tingkat kepatuhan masyarakat pada nilai igya ser hanjob hanya terlihat pada lokasi berkebun yang dilakukan di kawasan Susti, sedangkan pada masyarakat Arfak yang tidak berladang, kepatuhan menjadi semu dan terisolir (enclave culture). Nilai lokal perladangan berpindah dipertahankan, tetapi hanya mengangkang dalam sistem adat; dan (3) Secara statistik, pergeseran nilai kearifan lokal dipengaruhi secara langsung, signifikan dan positif oleh tingkat kepatuhan masyarakat terhadap kearifan lokal dan dipengaruhi secara tidak langsung, positif dan signifikan oleh karakteristik petani, aspek kelembagaan dan motivasinya.

\section{Saran}

Rekomendasinya, diperlukan pengaturan yang mengkolaborasikan norma lokal (adat) dengan norma formal (kebijakan) untuk melindungi dan mengakomodir nilai-nilai kearifan lokal.

\section{DAFTAR PUSTAKA}

Adimiharja, K. 1999. Petani Merajut Tradisi Era Globalisasi. Humaniora Utama Press, Bandung.

Akca, H., Murat Sayili and Ahmat Kurune. 2005. Trade of Between Multifunctionality Agriculture, Externality and an Environment. Pakistan Journal of Social Science 3(8).

Anthony Giddens. 2003. Masyarakat Post-Tradisional. IRCisoD, Yogyakarta

Asshiddiqie, Jimly. 2009. Green Constitution: Nuansa Hijau Undang-Undang Dasar Negara Republik Indonesia Tahun 1945. Rajawali Press, Jakarta.

Biswas, B. C. 2010. Farming System Approach To Improve IUE, Employment and Income in Eastern India. Fertilizer Marketing News 41(5):6-12.

Charles R. Ngangi. 2011. Konstruksi sosial dalam Realitas Sosial. ASE Volume 7 Nomor 2, Mei 2011

Cook, S and Macaulay P. 1997. Pemberdayaan yang Tepat. Elex Media Computindo, Jakarta.

Dinas Pertanian Provinsi Papua Barat. 2017. Laporan Tahunan Pertanian Papua Barat Tahun 2017. Pusdatin Papua Barat, Sorong.

Edy Suyanto, Sotyania W, FX Wardhiyono dan Hendri R. 2017. Social Engineering on Mangrove Preservation Based on Fishermen's Local Wisdom. Jurnal Mimbar Volume 33, No. 1, Tahun 2017. Unisba, Bandung

Eric Wolf. 1995. Perang Petani. Insist Press, Yogyakarta 
Fakih, M. 2001. Runtuhnya Teori Pembangunan dan Globalisasi. Insist Press, Yogyakarta.

Funes-Monzote, F.R. 2008. Farming like we're here to stay: The mixed farming alternative for Cuba. Ph.D. dissertation, Wageningen University, Wageningen.

Grootaert, C. 1997. Social Capital: The Missing Link? Environmentally and Socially Sustainable Development. The World Bank, New York.

Hannah Wittman. 2011. Food Sovereignty: A New Rights Framework for Food and Nature? Environment and Society: Advances in Research 2 (2011): 87-105 (C) Berghahn Books.

Herman Supriadi dan Handewi P. Sallem, 2004. Kondisi Sosial Ekonomi Dan Implikasi Kebijakan Terhadap Upaya Pengembangan Pertanian Di lahan Kering Marginal.

Hines, Colin. 2000. Localization: A Global Manifesto. Earthscan Publication LTD, London and Sterling, VA

International Food and Policy Research Institute (IFPRI). 2001. The Unfinished Agenda: Perspective on Overcoming Hunger, Poverty and Environmental Degradation. Edited by Per Pinstrup-Andersen and Rajul Pandya-Lorch. Washington D.C

Iskandar, Johan. 1992. Ekologi Perladangan di Indonesia: Studi Kasus dari Daerah Baduy Banten Selatan, Jawa Barat. Penerbit Djambatan, Jakarta.

Leakey, Roger R.B. 2017. Multifunctional Agriculture: Achieving Sustainable Development in Africa. Academic Press, UK

Marc Edelman, Tony Weis, Amita Baviskar, Saturnino M. Borras Jr., and Eric Holt-Giménez. 2014. Introduction: Critical Perspectives on Food Sovereignty. The Journal of Peasant Studies Publication details, including instructions for authors and subscription information:

http://www.tandfonline.com/loi/fjp $\underline{\mathrm{s} 20}$

Maudia C dan I. Setiawan. 2017. The Role Of Women Farmer Group In Increasing Family Welfare. Jurnal Mimbar, Volume 33, No. 2, Year 2017. Unisba, Bandung.

Muhammad Hujairin, Ahwan Ismadi, dan Tatan Kustana, 2012, Universitas Pertahanan,

Mulyadi. 2007. Pengadopsian Inovasi Pertanian Suku Pedalaman Arfak (Kasus di Kabapaten Manokwari. Papua Barat. Disertasi. Insertasi.Institut Pertanian Bogor.

Mulyadi. 2012. Budaya Pertanian Papua Perubahan Sosial dan Strategi Pemberdayaan Masyarakat Arfak. Yogyakarta: Karta Media.

Mulyana, D. 2000. Ilmu Komunikasi: Suatu Pengantar. Remaja Rosadakarya, Bandung.

Mulyo Utami, Elok; Endy S, Wim S, Subekti R dan Laxman J. 2004. Pengetahuan lokal petani dan inovasi ekologi dalam konservasi dan pengolahan tanah pada pertanian berbasis kopi di Sumberjaya, Lampung Barat, Jurnal Agrivita 26 (1): 98-107.

Nurul Qomar, Sambas B, Rinekso S dan Herwasono S. 2016. Local Institution in Utilization of the Water Resources of The Giam Siak Kecil - Bukit Batu Biosphere Reserve, in Riau, Indonesia. Jurnal Mimbar Volume 32, No. 2, Tahun 2016. Unisba, Bandung

Oades, LG., M Slade and A Jarden. 2017. Wellbeing and Recovery: A Possible Future. Cambridge 
University Press, UK.

Peter Rogers, Kazi F. Jalal dan John A. Boyd. 2007. An Introduction to Sustainable Development. Glen Educational Foundation, UK

Popkin, S.L. 1986. Petani Rasional. Yayasan Padamu Negeri, Jakarta.

Pranadji, T. 1999. Desentralisasi dan Percepatan Transformasi Agribisnis Secara Berkelanjutan. Dalam Dinamika Inovasi Sosial Ekonomi dan Kelembagaan Pertanian (Editor I.W. Rusastra dkk). Pusat Penelitian Sosial Ekonomi Pertanian. Bogor.

Purwanto, Y. 2003. Studi Etnoekologi Masyarakat Dani Baliem dan Perubahan Lingkungan di Lembah Baliem, Jaya Wijaya, Irian Jaya. Berita Biologi Volume 6, Nomor 5, Agustus 2003. Edisi Khusus Kebun Biologi Wamena dan Biodiversitas Papua.

Raj Patel. 2009. What does food sovereignty look like? The Journal of Peasant Studies Vol. 36, No. 3, July 2009, 663-706. https://www.tandfonline.com/actio n/journalInformation? journalCode $=$ fjps 20

Rakhmat, J. 1999. Psikologi Komunikasi. Remaja Rosda Karya, Bandung.

René Rohrbeck, L Konnertz and SF. Knab. 2013. Collaborative Business Modelling for Systemic and Sustainability Innovations. International Journal of Technology Management 63(1/2)

Romli M.S, Manuntun P.H dan Dominicus S. 2016. Transformasi Struktural: Faktor-faktor dan Pengaruhnya Terhadap Disparitas Pendapatan di Madura. Jurnal Ekonomi dan Kebijakan Pembangunan. Volume 5 Nomor 1. Edisi Juli, 2016

Salma Loudiyi. 2009. The Food Sovereignty Project: Advancing
Theory and Practices. Journal of Agriculture, Food Systems, and Community Development ISSN: 2152-0801 online https://www.foodsystemsjournal.or $\mathrm{g}$

Scott, J. 1993. Moral Ekonomi Petani: Pergolakan dan Subsistensi di Asia Tenggara. LP3ES, Jakarta.

Setiawan I, Sumardjo, A. Satria dan P. Tjitropranoto. 2015. Strategi Pengembangan Kemandirian Pelaku Muda Agribisnis " Brain Gain Actors" di Jawa Barat. Jurnal Mimbar, Volume 31, No. 2, Year 2015. Unisba, Bandung.

Setiawan I, Sumardjo, A. Satria dan P. Tjitropranoto. 2016. Studi Potensi Brain Gain di Dataran Tinggi: Kasus di Kabupaten Cianjur. Jurnal Sosiohumaniora, Volume 18, No.1, Tahun 2016. Unpad, Bandung.

Seunghyun Yoo, NE Weed, ML Lempa and RM Goodman. 2004. Collaborative Community Empowerment: An Illustration of a Six-Step Process. Journal of Health Promotion Practice 5(3):256-65

Simon, Hasanu. 2001. Pengelolaan Hutan Bersama Rakyat : Teori dan Aplikasi Pada Hutan Jati di Jawa. Bigraf Publishing, Yogyakarta.

Subagyono. 2004. Prospek Pengembangan ternak pola integrasi di kawasan perkebunan. Prosiding seminar nasional Sistem Integrasi Tanaman-Ternak. Denpasar 20-22 Juli 2004. Puslitbangnak, BPTP Bali dan CASREN. Boror, pp:13-17.

Sumardjo. 1999. Transformasi Model Penyuluhan Pertanian Menuju Pengembangan Kemandirian Petani. Disertasi. Sekolah Pascasarjana IPB, Bogor.

Supyandi, D., Y Sukayat dan M Rachmady. 2016. Participatory Plant Breeding: Kasus Pada 
Perbenihan Kedelai. Jurnal AGRICORE Volume 1 Nomor 2. Departemen Sosial Ekonomi Fakultas Pertanian Unpad, Bandung.

Suryana, Achmad, 2007. Menelisik UpayaMenggapai Ketahanan Pangan Nasional. Badan Penelitian dan Pengembangan Pertanian. Departemen Pertanian. Jakarta.

Thamrongwarangkul, A. 2001. For Out Thailand. Annual Report on Sustainable Community Development For Good Livelihoods And Environmental Project. Khon Kaen University.

Utomo, M., Eddy Rifai dan Abdulmuthalib Thahir. 1992. Pembangunan dan Alih Fungsi Lahan. Lampung. Unila, Lampung Van der Ploeg, Jan Douwe (2008). The New Peasantries: Struggles for Autonomy and Sustainability in an Era of Empire and Globalization. London and Sterling, VA: EARTHSCAN,

Vandana Shiva. 2002. Bebas dari Pembangunan. Yayasan Obor Indonesia, Jakarta

Wahyu dan I. Setiawan. 2017. BUMN Pangan: Evolusi Menuju Kedaulatan Pangan. Penebar Swadaya, Jakarta

Wanki Moon, Jae Bong Chang and Jebaraj Asirvatham. 2016.
Identifying Factors Driving US Citizens' Preferences about Multifunctional Agriculture. Southern Agricultural Economics Association 2016 Annual Meeting, San Antonio, Texas

Wanki Moon, Jae Bong Chang and Jebaraj Asirvatham. 2017. Measuring Public Preferences for Multifunctional Attributes of Agriculture in The United States. Journal of Agricultural and Applied Economics: page 1 of 23

Wanki Moon. 2012. Conceptualizing Multifunctional Agriculture from a Global Perspective. Sorthem Illinois University. Carbondale.

Wibowo, S.C. 1996. Analisis Pola Konversi Sawah Serta Dampaknya Terhadap Produksi Beras. IPB, Bogor

Wilson, G.A. 2007. Multifunctional Agriculture: A Transition Theory Perspective. CABI, Cromwell Press, UK

Wittman, H., 2010. Reconnecting agriculture \& the environment: food sovereignty \& the agrarian basis of ecological citizenship. dalam: Wittman, H., A. A. Desmarais, N. Wiebe, ed., 2010. Food sovereignty. Reconnecting food, nature and community. Oakland CA: Food First., hal.91105. 